\title{
Spectrum of Cutaneous Vasculitis in Adult Patients from the Farwaniya Region of Kuwait
}

\author{
Nawaf Al-Mutairi \\ Department of Dermatology, Farwaniya Hospital, Kuwait
}

Key Words

Cutaneous vasculitis, adults · Kuwait

\begin{abstract}
Objective: To determine the clinical profile, etiologic factors, disease associations, and the laboratory profile of adult patients with cutaneous leukocytoclastic vasculitis (LV) presenting to the Dermatology Department at Farwaniya Hospital, Kuwait. Subjects and Methods: The medical records of 57 adult patients ( $>18$ years) with biopsy-proven cutaneous LV from January 2004 to June 2006 at Farwaniya Hospital were reviewed. Results: Of the 57 patients studied, 21 (36.8\%) were classified as having primary cutaneous small vessel vasculitis. The most common type of skin lesions found was palpable purpura seen in 29 (50.9\%) patients. No possible cause for the cutaneous vasculitis could be identified in 21 patients. Extracutaneous involvement was seen in 32 (56.1\%) patients of which 29 had joint involvement. The most frequent laboratory abnormality was an elevated erythrocyte sedimentation rate (ESR). Altered laboratory evaluation in the form of leukocytosis, raised antistreptolysin $\mathrm{O}$ titers and urine abnormalities were found in association with systemic vasculitis. IgA deposits were present in 33 patients. Risk factors for chronicity of cutaneous LV were female sex, advanced age, unidentified etiology, absence of fever and presence of joint involvement. Conclusion: The commonest type of LV in Kuwait is primary cutaneous small vessel vasculitis. The most frequent laboratory abnormality associated with LV was increased ESR.

Copyright $\odot 2007$ S. Karger AG, Basel
\end{abstract}

\section{Introduction}

Vasculitis can range in severity from a self-limited single-organ disorder to a life-threatening disease with the prospect of multiple-organ failure [1]. The skin is commonly involved in vasculitic disorders reflecting systemic disease states as well as in the context of hypersensitivity disorders in which disease expression is largely confined to the skin. In the skin, the most frequent form of vasculitis is leukocytoclastic vasculitis (LV) [1]. Cutaneous LV is characterized histopathologically by segmental areas of transmural infiltration and disruption of the vessel architecture by neutrophils with fibrinoid necrosis [1]. The clinical hallmark is palpable purpura due to the infiltrate and hemorrhage. This condition may be localized to the skin alone or, less commonly, may be a manifestation of a systemic vasculitic syndrome with multiple extracutaneous end-organ involvement. Cutaneous LV is commonly associated with a wide spectrum of systemic inflammatory conditions, malignancies, infections, or drug hypersensitivities [2-4]. The natural course of the cutaneous lesions is unpredictable [2-4]. Risk factors to distinguish patients with a poor prognosis from those with a benign course have not been identified, and a rational therapy has not been standardized in this disorder $[5,6]$. To date there has been no study on cutaneous LV in Kuwait. Hence, the aim of this study was to retrospectively analyze the medical records of adult patients with histopathologically proven cutaneous LV.

Dr. Nawaf Al-Mutairi

Ass. Prof. of Dermatology, Faculty of Medicine

Kuwait University, PO Box 480

Farwaniya (Kuwait)

Tel. +965937 0203, Fax +965 480 8167, E-Mail nalmut@usa.net 


\section{Subjects and Methods}

The records of all adult patients from 2003 to 2006 with suspected cutaneous vasculitis and histopathologically proven cutaneous LV at the Department of Dermatology, Farwaniya Hospital, Kuwait, were reviewed. Age, sex, clinical history, possible etiologic factors, associated conditions and examination details of all the patients were recorded. A detailed perusal of the recorded history was done regarding the duration of vasculitis, constitutional and systemic symptoms, infections, drug intake, food allergy, malignancy, collagen vascular disease and any other coexisting systemic disorder.

The investigative profile of each patient was noted as shown in table 1 . The lesions selected for biopsy were those with less than 48-hour duration. For all cases, the biopsies were taken using deep punch biopsy method. The diagnosis of cutaneous LV was confirmed in all patients by the presence of an inflammatory infiltrate predominantly constituted by neutrophils, nuclear fragmentation, extravasation of erythrocytes, and necrosis of dermal vessel walls.

The clinical course was divided into acute (single episode of less than 3 months' duration) and chronic (prolonged course of over 3 months or at least two recurrent episodes over a period exceeding 3 months).

Patients were considered as having extracutaneous involvement as observed from the clinical assessment, biochemistry, radiology or histology. Renal involvement was defined as the presence of persistent glomerular hematuria and/or proteinuria.

\section{Biostatistical Analysis}

The $\chi^{2}$ test was done to compare observed and expected frequencies in primary and secondary types of cutaneous (localized) vasculitis and systemic vasculitis; frequencies in distribution of palpable purpura in various organs; frequencies for age, gender, etiology, constitutional symptoms, lesion distribution and morphology of lesions in the group of patients showing acute course versus the group showing chronicity/recurrences.

\section{Results}

From a total of 86 patients clinically suspected as having cutaneous LV, 57 were histopathologically proven cutaneous LV that were analyzed in this study. Of these 57 patients, 32 (56.1\%) were males and 25 (43.9\%) females, mean age 42.5 years, range $22-76$ years.

Various etiologies and/or other associated conditions associated with my cases are shown in table 2 . Just over a third of the patients (21 patients or $36.8 \%$ ) were classified as having primary cutaneous small vessel vasculitis, mostly the idiopathic limited cutaneous manifestation.

The spectrum of cutaneous manifestations of vasculitis observed in the patients is shown in table 3. The most common type was palpable purpura seen in 29 (50.9\%) patients, and of these 19 (33.3\%) were seen in the lower limbs. The $\chi^{2}$ analysis of the observed and expected fre-
Table 1. Laboratory evaluation for LV

Complete blood count with differential

ESR

Urine analysis, gross and microscopic

Liver function tests

Renal function tests

Chest X-ray

Infectious serology/cultures (blood, urine, swabs)

Hepatitis B and C

Cutaneous biopsy

Hematoxylin and eosin

Direct immunofluorescence

Any other special staining procedure as the case warrants

Stool guaiac

Cryoglobulins

Complement (CH50, C3, C4)

Rheumatoid factor

Antinuclear antibody

Antineutrophil cytoplasmic antibodies

Table 2. Etiologies and/or conditions associated with cutaneous LV in the 57 patients

\begin{tabular}{lc} 
Entity & Patients \\
\hline $\begin{array}{l}\text { Primary cutaneous (localized) vasculitis } \\
\text { Idiopathic }\end{array}$ & $21(36.8)$ \\
$\quad$ Urticarial vasculitis & $3(5.3)$ \\
Secondary cutaneous vasculitis & \\
$\quad$ Drug-induced & $10(17.5)$ \\
Infection-induced & $8(14.0)$ \\
Primary systemic vasculitis & $1(1.7)$ \\
Polyarteritis nodosa & $5(8.8)$ \\
Henoch-Schönlein purpura & $1(1.7)$ \\
Erythema elevatum diutinum & \\
Secondary systemic vasculitis & \\
Connective tissue disease & $1(1.7)$ \\
Systemic lupus erythematosus & $1(1.7)$ \\
Rheumatoid arthritis & $1(1.7)$ \\
Sjögren's syndrome & $1(1.7)$ \\
Malignancy & \\
Other disorders & $4(7.0)$ \\
Cryoglobulinemia (essential mixed) &
\end{tabular}

Figures in parentheses are percentages. $\mathrm{p}=0.5$ for observed compared to expected frequencies in primary and secondary types of cutaneous (localized) vasculitis and systemic vasculitis.

quencies in distribution of palpable purpura in different body areas led to the inference that palpable purpura is not influenced by types of vasculitis $(p>0.05)$.

Extracutaneous involvement (table 4) was seen in 32 patients (56.1\%). Joint involvement, arthralgias in 21 and 
Table 3. Cutaneous manifestations of LV in the 57 patients

\begin{tabular}{|c|c|c|c|}
\hline Cutaneous manifestation & Patients & $\begin{array}{l}\text { Localized } \\
\text { vasculitis }\end{array}$ & $\begin{array}{l}\text { Systemic } \\
\text { vasculitis }\end{array}$ \\
\hline Palpable purpura & $29(50.9)$ & & \\
\hline Lower extremity & $19(33.3)$ & $17(29.8)$ & $2(3.5)$ \\
\hline Above waist line & $6(10.5)$ & $5(8.8)$ & $1(1.8)$ \\
\hline Generalized & $4(7.0)$ & $3(5.3)$ & $1(1.8)$ \\
\hline Urticarial lesions & $4(7.0)$ & & \\
\hline Lower extremity & $3(5.3)$ & $3(5.3)$ & \\
\hline Above waist line & $1(1.8)$ & & $1(1.8)$ \\
\hline Generalized & 0 & & \\
\hline Ulcers & $6(10.5)$ & & \\
\hline Lower extremity & $3(5.3)$ & $3(5.3)$ & \\
\hline Above waist line & $1(1.8)$ & & $1(1.8)$ \\
\hline Generalized & $2(3.5)$ & $1(5.3)$ & $1(1.8)$ \\
\hline Nonpalpable purpura & $6(10.5)$ & & \\
\hline Lower extremity & $4(7.0)$ & $3(5.3)$ & $1(1.8)$ \\
\hline Above waist line & 0 & & \\
\hline Generalized & $2(3.5)$ & $1(1.8)$ & $1(1.8)$ \\
\hline Vesiculobullous lesions & $4(7.0)$ & & \\
\hline Lower extremity & $3(5.3)$ & $2(3.5)$ & $1(1.8)$ \\
\hline Above waist line & 0 & & \\
\hline Generalized & $1(1.8)$ & & $1(1.8)$ \\
\hline Livedo reticularis & $2(3.5)$ & & \\
\hline Lower extremity & $2(3.5)$ & $2(3.5)$ & \\
\hline Above waist line & 0 & & \\
\hline Generalized & 0 & & \\
\hline Nodules & $6(10.5)$ & & \\
\hline Lower extremity & $5(8.8)$ & $5(8.8)$ & \\
\hline Above waist line & 0 & & \\
\hline Generalized & $1(1.8)$ & & $1(1.8)$ \\
\hline
\end{tabular}

Figures in parentheses are percentages. $\mathrm{p}=0.07$ for observed compared to expected frequencies in distribution of palpable purpura in different body areas.

arthritis in 8 patients (mostly involving the knee), was seen in 29 cases.

The most frequent laboratory abnormality (table 5) was an elevated erythrocyte sedimentation rate (ESR) found in 29 patients. Altered laboratory evaluation in the form of leukocytosis (42.1\%), raised antistreptolysin O titers $(28 \%)$ and urine abnormalities (19.3\%) were found in association with systemic vasculitis. Eleven cases had urine abnormalities of which 6 had microscopic hematuria and proteinuria, and 5 had isolated proteinuria.

Direct immunofluorescence study showed IgA deposition in the dermal vessels in 33 (57.9\%) patients; of these, 5 were cases of Henoch-Schönlein purpura (HSP), 7 druginduced vasculitis, 1 rheumatoid arthritis and 20 were idiopathic. The results of direct immunofluorescence were negative for other immunoreactants tested except
Table 4. Extracutaneous associations of cutaneous LV in our patients

\begin{tabular}{lc}
\hline System involvement & Patients \\
\hline Fever & 18 \\
$\quad$ Cutaneous vasculitis & $6(6 / 18,33.3 \%)$ \\
$\quad$ Systemic vasculitis & $12(12 / 18,66.7 \%)$ \\
Joint involvement & 29 \\
$\quad$ Cutaneous vasculitis & $4(4 / 29,13.8 \%)$ \\
Systemic vasculitis & $25(25 / 29,86.2 \%)$ \\
Gastrointestinal & 8 \\
Renal & 16 \\
Pulmonary & 7 \\
Neurological & 0 \\
\hline
\end{tabular}

Table 5. Laboratory evaluation for LV

Test

Cuta- Sys-

neous temic

Complete blood count with differential

$\begin{array}{lll}\text { Raised TLC } & 3 & 21\end{array}$

ESR

Raised $\quad 9 \quad 20$

Urine analysis, gross and microscopic

Abnormal

110

Liver function tests WNL in all

Renal function tests WNL in all

Chest X-ray, NAD in all

Infectious serology/cultures (blood, urine, swabs)

ASO titer

Raised

$6 \quad 10$

Hepatitis B and C

Positive serology for hepatitis C virus $\quad 1$

Cutaneous biopsy

Hematoxylin and eosin, in all

Direct immunofluorescence, in all

Any other special staining procedure as the case warrants

Stool guaiac

Cryoglobulins

Complement (CH50, C3, C4)

Decreased

Rheumatoid factor

Antinuclear antibody

Antineutrophil cytoplasmic antibodies

TLC = Total leukocyte count; WNL = within normal limits; $\mathrm{NAD}=$ no abnormal diagnosis; $\mathrm{ASO}=$ antistreptolysin $\mathrm{O}$.

the deposition of IgG at the basement membrane in the case with systemic lupus.

The course of the disorder was acute in 34 cases (59.6\%) and chronic in $23(40.4 \%)$ as given in table 6 . Results of 
Table 6. Clinical characteristics of 34 cases showing an acute course versus 23 cases showing chronicity/recurrences

\begin{tabular}{|c|c|c|}
\hline Parameter & $\begin{array}{l}\text { Acute } \\
\text { course }\end{array}$ & $\begin{array}{l}\text { Chronicity/ } \\
\text { recurrences }\end{array}$ \\
\hline \multicolumn{3}{|l|}{ Age group* } \\
\hline $22-40$ & 26 & 7 \\
\hline$>40-76$ & 8 & 16 \\
\hline \multicolumn{3}{|l|}{$\operatorname{Sex}^{* *}$} \\
\hline Males & 22 & 8 \\
\hline Females & 12 & 15 \\
\hline \multicolumn{3}{|l|}{ Etiology } \\
\hline Identified & 29 & 7 \\
\hline Idiopathic & 5 & 16 \\
\hline \multicolumn{3}{|l|}{ Constitutional symptoms } \\
\hline Fever & 16 & 2 \\
\hline Joint involvement & 6 & 19 \\
\hline \multicolumn{3}{|l|}{ Lesion distribution } \\
\hline Lower extremities & 23 & 20 \\
\hline Lower extremities and above the waist & 5 & 3 \\
\hline \multicolumn{3}{|l|}{ Morphology of lesions } \\
\hline One type & 25 & 20 \\
\hline Multiple types & 9 & \\
\hline Ulcers & 3 & 1 \\
\hline Livedo & 1 & 1 \\
\hline
\end{tabular}

$\chi^{2}$ tests for various parameters showed that cases showing acute course and chronicity/recurrences are influenced by age ( $p \leq 0.001)$, gender ( $p \leq 0.05)$, etiology $(\mathrm{p} \leq 0.001)$ and constitutional symptoms ( $\mathrm{p} \leq 0.001)$, but not by lesion distribution ( $\mathrm{p}>0.05)$ and morphology of lesions ( $p>0.05)$.

A standard therapeutic pattern for the management of patients with cutaneous LV is shown in table 7. The patients showing chronicity or recurrences too could be effectively managed with a combination of various systemic agents.

\section{Discussion}

In this study primary cutaneous small vessel vasculitis represents the majority of patients $(36.8 \%)$ with cutaneous $\mathrm{LV}$, which is similar to the $40.7 \%$ incidence reported by Blanco et al. [1]. Tai et al. [7] reported an incidence of $61.3 \%$, which is higher compared to the present study. This might be explained by the fact that different researchers may use varying definitions of the vasculitic syndromes for classifying patients in different categories, such as the American College of Rheumatology criteria and the

Table 7. Therapeutic approach to the patients with cutaneous LV

\begin{tabular}{|c|c|c|}
\hline Category & Findings & Treatment \\
\hline General measures & $\begin{array}{l}\text { most cases of cutaneous LV representing } \\
\text { a self-limited short-lived episode }\end{array}$ & $\begin{array}{l}\text { confirm diagnosis } \\
\text { exclude systemic disease } \\
\text { remove triggers } \\
\text { leg elevation } \\
\text { avoid tight clothing } \\
\text { avoid cold exposure } \\
\text { antihistamines, aspirin, } \\
\text { NSAIDS }\end{array}$ \\
\hline Mild to limited skin disease & persistent/recurrent disease & $\begin{array}{l}\text { dapsone and/or colchicine } \\
\text { others: pentoxyphylline }\end{array}$ \\
\hline Moderate to severe skin disease & $\begin{array}{l}\text { extensive skin disease with vesicles, } \\
\text { ulcers, and/or nodules }\end{array}$ & $\begin{array}{l}\text { methotrexate, azathioprine, } \\
\text { and/or prednisolone } \\
\text { others: hydroxychloroquine, } \\
\text { cyclosporine, } \\
\text { cyclophosphamide }\end{array}$ \\
\hline Systemic vasculitis present & $\begin{array}{l}\text { skin and other organ disease with risk } \\
\text { of death/permanent damage }\end{array}$ & $\begin{array}{l}\text { prednisolone } \pm \\
\text { cyclophosphamide or } \\
\text { azathioprine or } \\
\text { cyclosporine or } \\
\text { mycophenolate mofetil }\end{array}$ \\
\hline
\end{tabular}


Chapel Hill Congress Conference definitions, which identify different patients [5, 6, 8-11]. Equally important is the absence of any underlying cause or association that could be identified for this group of patients, consistent with recent reports in which about $40-60 \%$ of all cases of cutaneous vasculitis are idiopathic [5-12]. The low incidence of HSP in this study is reflective of the fact that HSP mainly involves children [5] in accordance with other studies [1, $5,7]$. Drugs and infections contributed to cutaneous vasculitis in $31.6 \%$ of our patients, which is consistent with a previous report by Carlson et al. [5]. Antibiotics were the commonest cause of drug-induced vasculitis as reported previously by García-Porrúa et al. [13].

Palpable purpura constituted the most common manifestation of cutaneous LV in this study, mirroring other studies [14-16], and it has been identified as the most sensitive diagnostic sign for cutaneous LV [17].

The natural history of LV depends on the degree of systemic involvement $[1,5]$. Multisystem organ involvement has been reported in up to $50 \%$ of patients, most commonly in the small vessels of the kidneys, gastrointestinal tract, joints, muscles, lungs, and peripheral nerves [18], similar to the present findings.

The incidence of IgA deposits in skin lesions (57.9\%) in this study is comparable to the $40 \%$ [19] and 17\% [20] reported in other studies. In a recent report [21], IgA was the immunoglobulin most frequently detected in blood vessels of both skin lesion (82\%) and perilesion (68\%), thereby leading to the suggestion that the presence of $\operatorname{Ig} \mathrm{A}$, in involved and uninvolved skin, although not pathognomonic, can be considered as highly sensitive and specific for the diagnosis of cutaneous LV, indepen- dent of the existence of extracutaneous involvement [21].

Certain parameters showed a remarkable contrast in the two groups of patients, one showing an acute course and the other showing a chronic course or a course marked by recurrences. Risk factors for chronicity were female sex, advanced age, unidentified etiology, absence of fever and presence of joint involvement in my patients. Presence of arthralgia and absence of fever have already been identified as predictive factors for chronicity of $\mathrm{cu}-$ taneous LV [22].

The treatment of cutaneous LV is by and large empiric in nature as few randomized control trials have been performed. The treatment has to be tailored to disease severity and the risk for permanent organ damage [5].

\section{Conclusion}

Although the relatively benign condition of primary cutaneous small vessel vasculitis is the commonest type encountered in adults, a wide spectrum of clinical associations and laboratory anomalies have been observed. Risk factors for chronicity are female sex, advanced age, unidentified etiology, absence of fever and presence of joint involvement. As the patient's management and prognosis depend on the presence or absence of an underlying disease or association, adults need a thorough diagnostic workup and a more extensive evaluation to look for possible extracutaneous involvement. Failure to recognize this may result in significant patient morbidity and mortality.

\section{References}

$>1$ Blanco R, Martinez-Taboada VM, Rodriguez-Valverde V, Garcia-Fuentes M: Cutaneous vasculitis in children and adults: associated diseases and etiologic factors in 303 patients. Medicine (Baltimore) 1998;77:403418.

-2 Jennette JC, Falk RJ, Milling DM: Pathogenesis of vasculitis. Semin Neurol 1994;14:291299.

-3 Mandell BF, Hoffman GS: Differentiating the vasculitides. Rheum Dis Clin North Am 1994;20:409-442.

4 Swerlick RA, Lawley TJ: Cutaneous vasculitis: its relationship to systemic disease. Med Clin North Am 1989;73:1221-1235.

5 Carlson JA, Cavaliere LF, Grant-Kels JM: Cutaneous vasculitis: diagnosis and management. Clin Dermatol 2006;24:414-429.
6 Carlson JA, Ng BT, Chen KR: Cutaneous vasculitis update: diagnostic criteria, classification, epidemiology, etiology, pathogenesis, evaluation and prognosis. Am J Dermatopathol 2005;27:504-528.

7 Tai YJ, Chong AH, Williams RA, Cumming S, Kelly RI: Retrospective analysis of adult patients with cutaneous leukocytoclastic vasculitis. Australas J Dermatol 2006;47:9296.

8 Sorensen SF, Slot O, Tvede N, Petersen J: A prospective study of vasculitis patients collected in a five year period: evaluation of the Chapel Hill nomenclature. Ann Rheum Dis 2000;59:478-482. $\checkmark 9$ Rao JK, Allen NB, Pincus T: Limitations of the 1990 American College of Rheumatology classification criteria in the diagnosis of vasculitis. Ann Intern Med 1998;129:345352.

10 Lane SE, Watts RA, Shepstone L, Scott DG: Primary systemic vasculitis: clinical features and mortality. QJM 2005;98:97-111.

11 Lane SE, Watts RA, Barker TH, Scott DG: Evaluation of the Sorensen diagnostic criteria in the classification of systemic vasculitis. Rheumatology (Oxford) 2002;41:1138-1141.

12 Lotti T, Ghersetich I, Comacchi C, Jorizzo JL: Cutaneous small-vessel vasculitis. J Am Acad Dermatol 1998;39:667-687. 
13 García-Porrúa C, González-Gay MA, LópezLázaro L: Drug associated cutaneous vasculitis in adults in northwestern Spain. J Rheumatol 1999;26:1942-1944.

- 14 Sais G, Vidaller A, Jucgla A, Servitje O, Condom E, Peyri J: Prognostic factors in leukocytoclastic vasculitis: a clinicopathologic study of 160 patients. Arch Dermatol 1998; 134:309-315.

15 Hodge SJ, Callen JP, Ekenstam E: Cutaneous leukocytoclastic vasculitis: correlation of histopathological changes with clinical severity and course. J Cutan Pathol 1987;14: 279-284.
16 Ekenstam Eaf, Callen JP: Cutaneous leukocytoclastic vasculitis: clinical and laboratory features of 82 patients seen in private practice. Arch Dermatol 1984;120:484-489.

17 Calabrese LH, Michel BA, Bloch DA, Arend WP, Edworthy SM, Fauci AS, Fries JF, Hunder GG, Leavitt RY, Lie JT, et al: The American College of Rheumatology 1990 criteria for the classification of hypersensitivity vasculitis. Arthritis Rheum 1990;33:11081103.

18 Callen JP: Vasculitis; in Callen JP, Jorizzo JL, Greer KE, et al (eds): Dermatological Signs of Internal Disease, ed 2. Philadelphia, Saunders, 1995, pp 31-34.

19 Mackel SE, Jordon RE: Leukocytoclastic vasculitis: a cutaneous expression of immune complex disease. Arch Dermatol 1982;118: 296-301.
20 Grunwald MH, Avinoach I, Amichai B, Halevy S: Leukocytoclastic vasculitis: correlation between different histologic stages and direct immunofluorescence results. Int Dermatol 1997;36:349-352.

21 Barnadas MA, Perez E, Gich I, Llobet JM, Ballarin J, Calero F, Facundo C, Alomar A: Diagnostic, prognostic and pathogenic value of the direct immunofluorescence test in cutaneous leukocytoclastic vasculitis. Int J Dermatol 2004;43:19-26.

22 Sais G, Vidaller A, Jucgla A, Servitje O, Condom E, Peyri J: Prognostic factors in leukocytoclastic vasculitis: a clinicopathologic study of 160 patients. Arch Dermatol 1998; 134:309-315. 